\title{
Mechanically and thermally stable, transparent electrodes with silver nanowires encapsulated by atomic layer deposited aluminium oxide for organic optoelectronic devices
}

\author{
Shuanglong Wang ${ }^{\mathrm{a}, \mathrm{b}, 1}$, Shiwei Wu ${ }^{\mathrm{a}, 1}$, Zhitian Ling ${ }^{\mathrm{a}}$, Huimin Chen ${ }^{\mathrm{a}}$, Hong Lian ${ }^{\mathrm{a}}$, \\ Xavier Portier $^{\mathrm{c}}$, Fabrice Gourbilleau ${ }^{\mathrm{c}}$, Tomasz Marszalek ${ }^{\mathrm{b}}$, Furong Zhu ${ }^{\mathrm{d}}$, Bin Wei ${ }^{\mathrm{a}}$, Tao Xu ${ }^{\mathrm{a}, *}$ \\ ${ }^{a}$ School of Mechatronic Engineering and Automation, Key Laboratory of Advanced Display and System Applications, Ministry of Education, Shanghai University, \\ 200072, Shanghai, China \\ ${ }^{\mathrm{b}}$ Max Planck Institute for Polymer Research, Ackermannweg 10, 55128, Mainz, Germany \\ ' CIMAP, Normandie Univ, ENSICAEN, UNICAEN, CEA, CNRS, 6 Boulevard Maréchal Juin, 14050, Caen Cedex 4, France \\ ${ }^{\mathrm{d}}$ Department of Physics, Research Centre of Excellence for Organic Electronics and Institute of Advanced Materials, Hong Kong Baptist University, Kowloon Tong, Hong \\ Kong, China
}

\begin{abstract}
A B S T R A C T
Flexible conductive electrodes are essential components for organic optoelectronic devices (OODs). One of the main challenges in the development of flexible OODs is to achieve an optimal combination of photoelectrical properties, enhanced flexibility and stability in transparent conductive electrodes (TCEs). In this work, highperformance flexible nonfullerene organic solar cells (OSCs) and polymer light-emitting diodes (PLEDs) based on TCEs of silver nanowires (AgNWs) encapsulated with an ultra-thin atomic layer deposited aluminum oxide $\left(\mathrm{Al}_{2} \mathrm{O}_{3}\right)$ have been demonstrated. The hybrid $\mathrm{AgNWs} / \mathrm{Al}_{2} \mathrm{O}_{3}$ composite electrodes with enhanced thermal, ambient and mechanical stabilities enable an efficient flexible transparent electrode with high transmittance and conductivity, which can synergistically optimize the device performance of nonfullerene OSCs and PLEDs. The maximum power conversion efficiency value of 7.03\%, as well as a current efficiency of $7.26 \mathrm{~cd} \mathrm{~A}{ }^{-1}$ for flexible OSCs and PLEDs are achieved, respectively. Notably, excellent flexibility, long-term atmospheric and thermal stabilities have been systematically investigated and demonstrated. These results provide a new design platform for the fabrication of high-performance, flexible transparent electrodes, which can be further explored in a wide range of organic optoelectronics field.
\end{abstract}

Keywords:

Silver nanowires

Atomic layer deposition

Nonfullerene organic solar cells

Polymer light-emitting diodes

Flexible

Stability

\section{Introduction}

New-generation organic optoelectronic devices (OODs) such as organic solar cells (OSCs) and polymer light-emitting devices (PLEDs) have appealed great interest and are promising candidates in solid-state lighting and renewable energy applications due to their distinct advantages of large-scale solution processing, cost-effective and flexibility [1-4]. High-performance foldable and transformable conductive electrodes are a critical component for flexible OSCs and PLEDs, which need to be optimized by high transmittance in the visible-light region, excellent electrical conductivity and mechanical stability $[5,6]$. Currently, the most commercially used transparent electrode in OODs is indium-tin-oxide (ITO). However, its role in flexible and wearable electronics is limited because of its inherent drawbacks of rigidity, brittleness, the scarcity of indium, as well as high-temperature and high-vacuum deposition processing technique $[7,8]$. Consequently, these shortcomings of ITO incite the development of novel flexible transparent electrodes (FTEs) for new generation optoelectronics. Nowadays, alternative materials for FTEs have been developed to replace ITO including graphene, carbon nanotubes, polymers, metal grids and metallic nanowires [9-13]. Among these materials, silver nanowires (AgNWs) are an appealing candidate because of the appropriate opto-electrical properties, large area and roll-to-roll processing [14-16]. Recently, a high-performance top-illuminated all-solution-processed flexible OSC, comprising of a polymer/AgNWs-based transparent top anode has been demonstrated 
[17].

Despite significant advantages over competitors to replace ITO, several problems should be solved for AgNWs-based FTEs [18]. Firstly, during the solution depositing process, the randomly distributed nanowires could become protuberant, resulting in large surface roughness. Secondly, due to the nanoscale size effect, AgNWs tend to melt at a significantly lower temperature $\left(\sim 200{ }^{\circ} \mathrm{C}\right)$ comparing with the bulk silver. Furthermore, the electrical properties of AgNWs may become instable due to long-lasting Joule heating at the junctions between AgNWs [19]. Thirdly, the AgNWs suffer rapid oxidation when exposed to humid air. So the chemical stability of the electrode in organic electronic devices requires amelioration. When the AgNWs worked as a transparent electrode in OODs on which the poly(3, 4-ethylenedioxythiophene):poly(styrenesulfonate) (PEDOT:PSS) solution is subsequently deposited, the acidity of PEDOT:PSS can severely damage the AgNWs electrode [20]. Many strategies have been explored to address the aforementioned shortcomings of AgNWs-based FTEs. For example, it has been reported that the use of neutral-pH PEDOT:PSS as the modification layer can improve chemical stability of AgNWs electrode, but the performance of resulting AgNWs/PEDOT:PSS composite electrode is still limited because of the degradation of PEDOT:PSS at a certain high temperature [21]. A tandem layer of zinc oxide (ZnO)/AgNWs/ZnO was reported to enhance the thermal stability of the AgNWs. However, a large thickness of $\mathrm{ZnO}$ film $(\sim 33 \mathrm{~nm})$ is needed to ensure the protection of AgNWs using sputtering method, which hinders the widespread use for large-area applications [22]. As a result, it is still necessary to develop an effective encapsulation layer on AgNWs-based electrodes.

An effective method is to use the low-temperature atomic layer deposition (ALD) processing, taking its unique advantage of precise thickness control, excellent conformal and pin-hole free coverage ability [23,24]. Indeed, ALD deposited metal oxide films are usually introduced in commercial silicon based solar cell production, whereas there are few literatures about the OODs using this method [25,26]. Recently, Hwang et al. reported that an ultra-thin layer of ALD processed aluminum oxide $\left(\mathrm{Al}_{2} \mathrm{O}_{3}\right)$ film grow perpendicularly on the surface of AgNWs, making a perfect conformal coating around individual nanowire and junction, which can effectively improve thermal, chemical and mechanical stabilities of the AgNWs-based FTEs [27]. It is also reported that use of ALD-ZnO coated AgNWs can be applied in PLEDs as FTEs [28]. However, the device performances have not been optimized and the versatility of this method in diverse OODs needs to be further explored.

In this work, we reported a low temperature processed highperformance flexible FTEs based on AgNWs encapsulated by atomic layer deposited ultra-thin $\mathrm{Al}_{2} \mathrm{O}_{3}$ films. The resulting composite electrode showed excellent mechanical flexibility, long-term atmospheric and thermal stabilities. The surface morphology and the interface structure of $\mathrm{AgNWs} / \mathrm{Al}_{2} \mathrm{O}_{3}$ composite electrode were systematically analyzed by means of scanning electron microscope (SEM), atomic force microscopy (AFM), high-resolution transmission electron microscopy (TEM) and chemical mapping by energy dispersive X-ray (EDX) spectroscopy. Such FTEs were applied in different flexible OODs, giving a high power conversion efficiency (PCE) of $7.03 \%$ in flexible nonfullerene OSCs, as well as a current efficiency (CE) of $7.26 \mathrm{~cd} \mathrm{~A}^{-1}$ in PLEDs. Finally, the flexible devices demonstrated excellent mechanical and storage stability, illustrating promising application potentials of the $\mathrm{AgNWs} / \mathrm{Al}_{2} \mathrm{O}_{3}$ FTEs in a variety of efficient and robust OODs.

\section{Experiment section}

\subsection{Materials}

AgNWs solution was ordered from BlueNano Company. The average diameter and length of the AgNWs are about 30-60 nm and 15-30 $\mu \mathrm{m}$, respectively. Poly(methyl methacrylate) (PMMA), Chlorobenzene and 1,8-diiodooctane were ordered from Sigma Aldrich. PEDOT:PSS was ordered from Heraeus. Nonfullerene active materials poly[(2,6-(4,8-bis (5-(2-ethylhexyl)thiophen-2-yl)-benzo[1,2-b:4,5-b']dithiophene))-alt(5,5-(1',3'-di-2-thienyl-5', $7^{\prime}$-bis(2-ethylhexyl)benzo[1', $2^{\prime}$-c: $4^{\prime}, 5^{\prime}$-c'] dithiophene-4,8-dione))] (PBDB-T) and 3,9-bis(2-methylene-(3-(1,1dicyanomethylene)-indanone))-5,5,11,11-tetrakis(4-hexylphenyl)dithieno[2,3d:2',3'-d']-s-indaceno[1,2-b:5,6-b'] dithiophene) (ITIC) were ordered from Solarmer. Super Yellow PPV (SY-PPV, PYD-132) was purchased from Xi'an Polymer Light Technology Corp. The smallmolecular material 8-Hydroxyquinolinolato-lithium (Liq) was purchased from e-Ray Optoelectronics Corp. Polyethylene terephthalate (PET) substrates were purchased from CSG Holding Co. Ltd. All chemicals and regents purchased with commercial sources in this work were used as received unless otherwise stated.

\subsection{Fabrication of $\mathrm{AgNWs} / \mathrm{Al}_{2} \mathrm{O}_{3}$ FTEs}

The PET substrate was firstly washed by detergent, de-ionized water and ethanol, respectively. PMMA solution $\left(80 \mathrm{mg} \mathrm{ml}^{-1}\right)$ was then spincoated on PET for $60 \mathrm{~s}$ at a speed of $1000 \mathrm{rpm}$, followed by an annealing at $110^{\circ} \mathrm{C}$ for $10 \mathrm{~min}$. Then, AgNWs solution was deposited on the PMMA covered PET slide prior to annealing at $110{ }^{\circ} \mathrm{C}$ for $15 \mathrm{~min}$ to remove residual solvents. After that, mechanical pressure was loaded by a custom-made compressor controlled by an air pressure boosting device. The substrates were finally transferred into a vacuum chamber of ALD. $\mathrm{Al}_{2} \mathrm{O}_{3}$ layers with five different thicknesses of $1,2,4,10$ and $20 \mathrm{~nm}$ were deposited by using ALD technique. The ALD deposition processing was carried out in a TFS200 Beneq and the trimethylaluminum and $\mathrm{H}_{2} \mathrm{O}$ were employed as the reactants. The deposition rate of $\mathrm{Al}_{2} \mathrm{O}_{3}$ was 0.1 $\mathrm{nm} /$ cycle and the growth temperature was $110^{\circ} \mathrm{C}$. The thickness of the $\mathrm{Al}_{2} \mathrm{O}_{3}$ was accurately fixed by controlling the cycle numbers.

\subsection{Fabrication of flexible nonfullerene OSCs and PLEDs}

The device structure of flexible nonfullerene OSCs was PET/FTEs/ PEDOT:PSS/PBDB-T:ITIC/Liq/Al. Here, PEDOT:PSS used as hole injection layer (HIL) was filtered through a $0.45 \mu \mathrm{m}$ syringe filter and deposited to the FTEs/PET substrate by spin-coating at a speed of 3000 $\mathrm{rpm}$, and then annealed at $110{ }^{\circ} \mathrm{C}$ for $30 \mathrm{~min}$. Active layer of PBDB-T: ITIC was then spin-coated at $2000 \mathrm{rpm}$ for $60 \mathrm{~s}$, while the thickness of the active films was about $110 \mathrm{~nm}$. To fabricate the active layer, $10 \mathrm{mg}$ of PBDB-T and $10 \mathrm{mg}$ of ITIC were dissolved in $1 \mathrm{~mL}$ of chlorobenzene, mixed with $0.03 \mathrm{~mL}$ of 1,8-diiodooctane. Finally, Liq (1 nm) and $\mathrm{Al}(100$ $\mathrm{nm}$ ) were thermally evaporated onto the active layer in a vacuum evaporation system by using a shadow mask at a base pressure of about $1 \times 10^{-5}$ mbar. The deposition rates for the organic functional materials and $\mathrm{Al}$ electrode were 0.6 and $5.0 \AA_{\mathrm{s}}^{-1}$, respectively.

For the fabrication of flexible PLEDs, the SY-PPV material dissolved in toluene with the concentration of $5 \mathrm{mg} \mathrm{mL}^{-1}$ and filtered before the deposition on the PEDOT:PSS HIL at $1000 \mathrm{rpm}$ for $60 \mathrm{~s}$ to output an uniform emission layer (EML). Then the EML was thermally annealed at $60{ }^{\circ} \mathrm{C}$ for $20 \mathrm{~min}$. PEDOT:PSS HIL and Liq/Al were processed as previously described for the flexible nonfullerene OSCs.

\subsection{Characterization}

The optical transmittances and sheet resistances $\left(R_{S}\right)$ of the transparent electrodes were measured by using a UV-vis spectrophotometer (HITACHI Ue3900H) and a 4-point probe system (RS8, BEGA Technologies), respectively. All the results are measured at least five times to obtain the average values. The surface morphological images of the $\mathrm{AgNWs} / \mathrm{Al}_{2} \mathrm{O}_{3}$ electrodes were analyzed by using SEM (HITACHI S4800) and AFM (Nanonavi SPA-400SPM). The TEM samples were prepared by using a Focused Ion Beam (FIB) system (HELIOS Nanolab 600 from FEI). Transmission electron microscopy observations were performed using a double corrected ARM200F cold FEG JEOL microscope operated at $200 \mathrm{kV}$ and equipped with an energy dispersive X-Ray (EDX) 
spectrometer (CENTURIO from JEOL). Scanning transmission electron microscopy (STEM) combined with a High Angle Annular Dark field Detector (HAADF) allowed chemical analyses. STEM EDX mapping was also carried out and the chemical maps presented hereafter are $256 \mathrm{x}$ 256 maps, with an acquisition time of 5 msec per pixel and about 1000 counts per seconds. All the digitized images were recorded and analyzed with DIGITAL MICROGRAPH (DM2 version) from GATAN.

The typical current density versus voltage $(J-V)$ characteristics of the flexible nonfullerene OSCs were tested with a source meter (Keithley 2400) under illumination of $100 \mathrm{~mW} \mathrm{~cm} \mathrm{~cm}^{-2}$ with AM $1.5 \mathrm{G}$ simulated solar spectrum. The external quantum efficiency (EQE) spectra of the solar cells were measured on a 7-SCSpec solar cell measurements system. The current density-voltage-luminescence $(J-V-L)$ characteristics of PLEDs were tested using a PR-650 Spectra Colorimeter and a Keithley 2400 source meter. The mechanical flexibility of the nonfullerene OSCs and PLEDs was tested using a custom-made bending test machine and the bending radius was $5 \mathrm{~mm}$. All the stability of the resulting device was measured with a simple UV curing epoxy resin encapsulation.

\section{Results and discussion}

The fabrication process of the $\mathrm{AgNWs} / \mathrm{Al}_{2} \mathrm{O}_{3}$ FTEs is illustrated in Fig. 1a. Briefly, AgNWs were first deposited on the PMMA/PET substrate by spin-coating, then pressed partially into PMMA matrix to reduce the surface roughness. Ultra-thin $\mathrm{Al}_{2} \mathrm{O}_{3}$ films with various thicknesses were finally deposited onto AgNWs. SEM images of the $\mathrm{AgNWs} / \mathrm{Al}_{2} \mathrm{O}_{3}$ composite films clearly show that the average diameter of the underlying AgNWs network increases with the thickness of the $\mathrm{Al}_{2} \mathrm{O}_{3}$ encapsulation layer from 0 to $2 \mathrm{~nm}$, giving evidence of the good coverage of $\mathrm{Al}_{2} \mathrm{O}_{3}$ layer on the surface, as shown in Fig. 1b-d. The SEM images for AgNWs encapsulated with 4, 10, and $20 \mathrm{~nm}$ of $\mathrm{Al}_{2} \mathrm{O}_{3}$ are illustrated in Fig. S1. It is known that smooth morphology and uniform coverage of $\mathrm{Al}_{2} \mathrm{O}_{3}$ encapsulation layer on AgNWs electrode are important for minimizing the roughness and potential leakage current generated in organic devices. Here, AFM observations were used to further analyze the surface morphologies of the resulting $\mathrm{AgNWs} / \mathrm{Al}_{2} \mathrm{O}_{3}$ FTEs. The AFM images (Fig. $1 \mathrm{e}-\mathrm{g}$ ) of the $\mathrm{AgNWs} / \mathrm{Al}_{2} \mathrm{O}_{3}$ network show larger diameter for AgNWs encapsulated by $\mathrm{Al}_{2} \mathrm{O}_{3}$ layers, which are consistent with the SEM analysis.

To validate the thermal stability of the electrodes coated with $\mathrm{Al}_{2} \mathrm{O}_{3}$ layer at high temperature, AgNWs encapsulated by $\mathrm{Al}_{2} \mathrm{O}_{3}$ layer with various thickness $(0,1$ and $2 \mathrm{~nm})$ were annealed at 150,200 , and $250{ }^{\circ} \mathrm{C}$ for $30 \mathrm{~min}$ in atmosphere. It has been reported that an abrupt decrease in electrical performance can be observed at temperatures above $180{ }^{\circ} \mathrm{C}$ [29]. Fig. 2 shows the evolution of the surface morphologies of $\mathrm{AgNWs} / \mathrm{Al}_{2} \mathrm{O}_{3}$ composite films under various thermal conditions. Both pristine and $\mathrm{Al}_{2} \mathrm{O}_{3}$ coated $\mathrm{AgNWs}$ were found to remain intact in networks at $150{ }^{\circ} \mathrm{C}$. However, the coalescence of the nanowires into droplets were observed at $200{ }^{\circ} \mathrm{C}$ for pristine AgNWs, as shown in Fig. 2b. After annealing at $250^{\circ} \mathrm{C}$, most of the AgNWs agglomerated into balls and the SEM image showed only discrete Ag nanoparticles (see Fig. 2c). The low magnification image of pristine AgNWs annealed at $250{ }^{\circ} \mathrm{C}$ is shown in Fig. S2. It is expected that the thermal stability of AgNWs coated with $\mathrm{Al}_{2} \mathrm{O}_{3}$ can be greatly enhanced. $\mathrm{Al}_{2} \mathrm{O}_{3}$ has a relatively high melting temperature close to $2070{ }^{\circ} \mathrm{C}$ which greatly exceeds that of silver. Even nanoscale alumina film can withstand high annealing

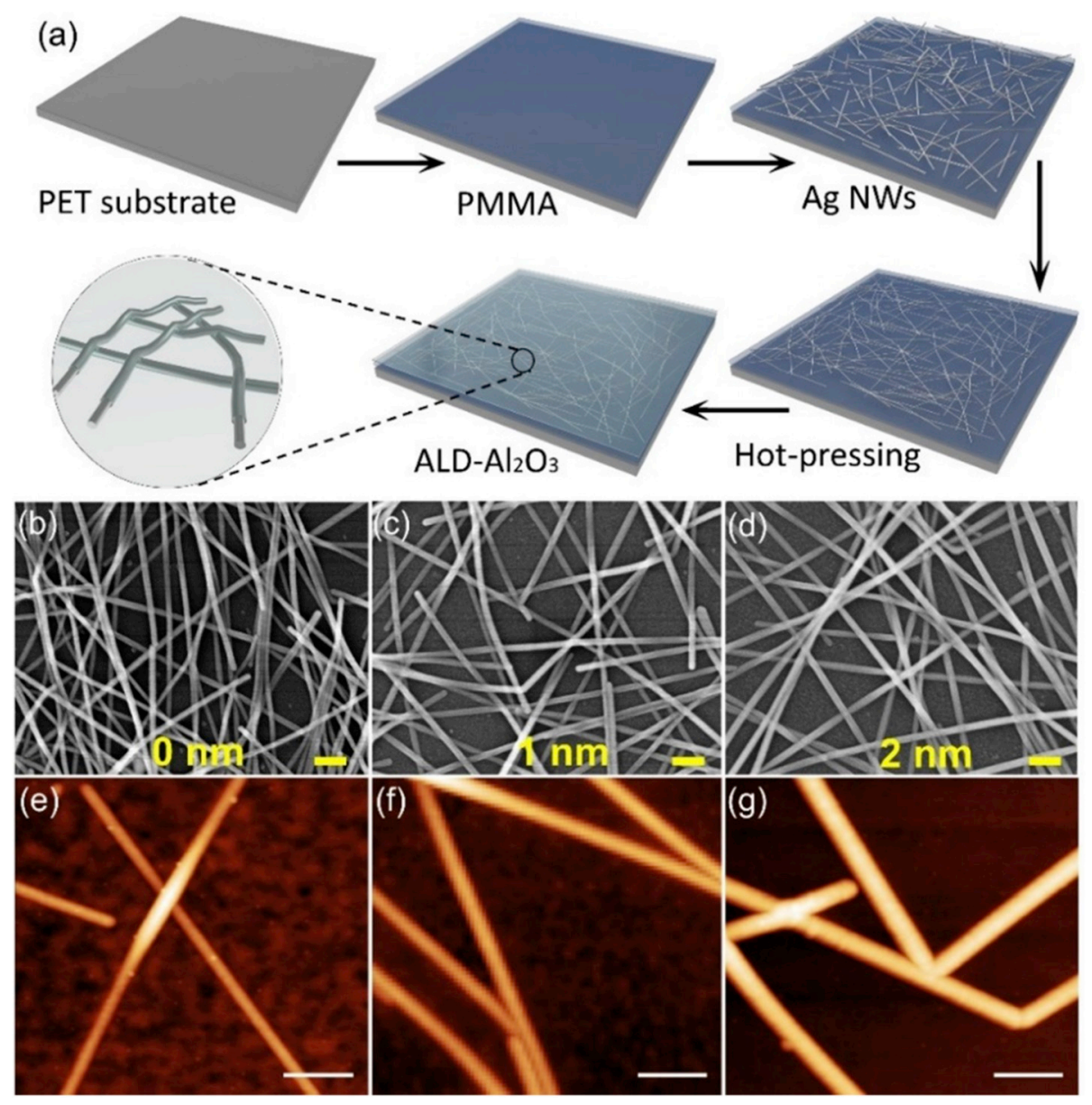

Fig. 1. (a) Schematic representation of the fabrication of the $\mathrm{AgNWs} / \mathrm{Al}_{2} \mathrm{O}_{3}$ composite films. SEM images of (b) pristine $\mathrm{AgNWs}$ and $\mathrm{AgNWs} / \mathrm{Al}_{2} \mathrm{O}_{3}$ composite films with various $\mathrm{Al}_{2} \mathrm{O}_{3}$ thicknesses of (c) $1 \mathrm{~nm}$ and (d) $2 \mathrm{~nm}$ (The scale bar is $200 \mathrm{~nm}$ ). (e-g) AFM images of AgNWs/ $\mathrm{Al}_{2} \mathrm{O}_{3}$ composite films corresponding to (b-d). The scale bar is $200 \mathrm{~nm}$. 


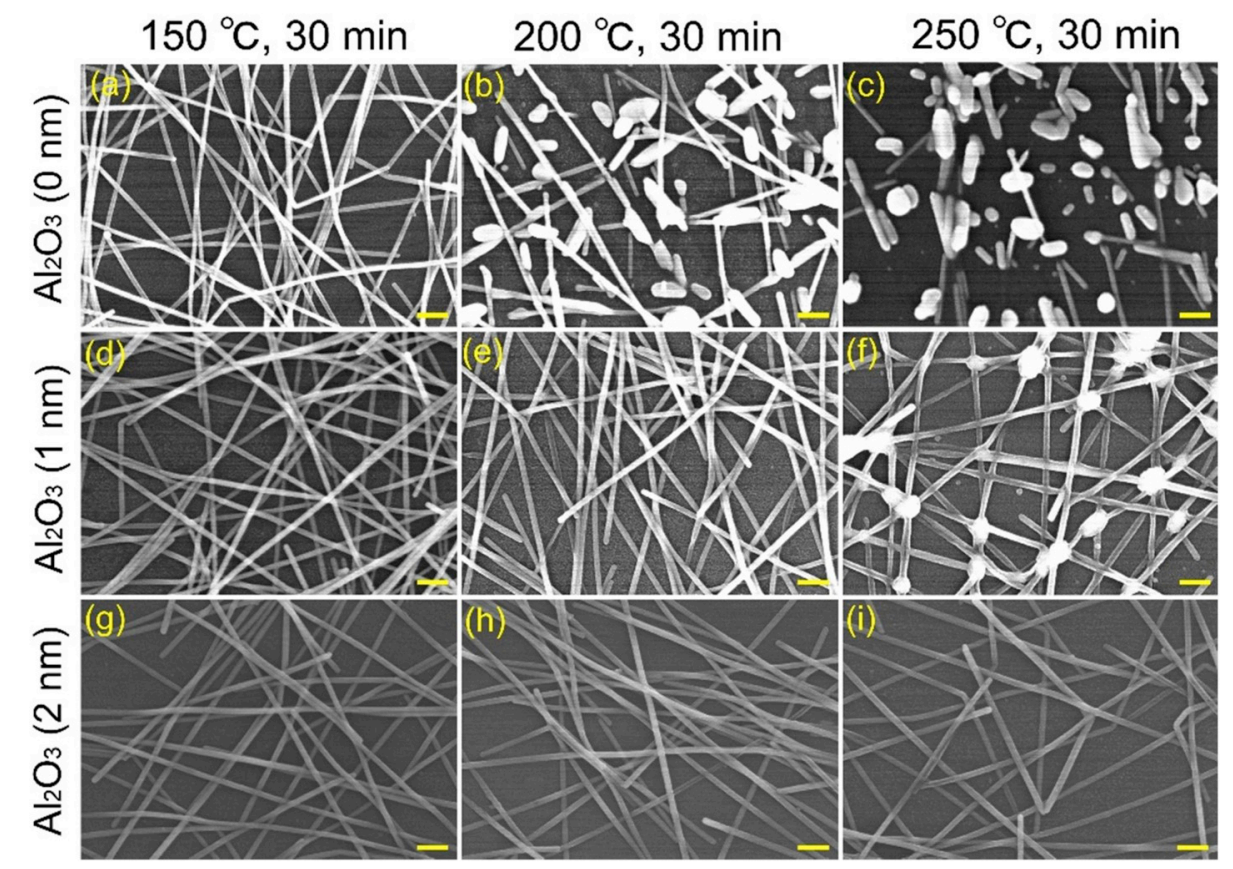

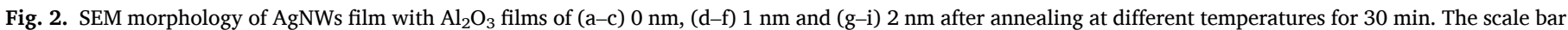
is $200 \mathrm{~nm}$.

temperatures, well over the processing temperatures required for general optoelectronic devices processing [30]. In addition, some works has reported that the trimethyl-aluminum precursor of $\mathrm{ALD}-\mathrm{Al}_{2} \mathrm{O}_{3}$ can adsorb strongly on $\mathrm{Ag}$ surface, resulting in the conformal $\mathrm{Al}_{2} \mathrm{O}_{3}$ encapsulation on the AgNWs [31]. When $\mathrm{Al}_{2} \mathrm{O}_{3}$ layers were coated onto AgNWs, no samples showed agglomeration on the junctions. For samples heated at $250{ }^{\circ} \mathrm{C}$, the sample with an $\mathrm{Al}_{2} \mathrm{O}_{3}$ layer thickness of $1 \mathrm{~nm}$ shows a few droplets and junction deterioration, as shown in Fig. 2f, which could be attributed to incomplete coverage of the $\mathrm{Al}_{2} \mathrm{O}_{3}$ coating at low thickness. For comparison, the AgNWs electrode remained the same morphology with no significant coalescence even after annealing at 250
${ }^{\circ} \mathrm{C}$ with the thickness of $\mathrm{Al}_{2} \mathrm{O}_{3}$ layer up to $2 \mathrm{~nm}$, as shown in Fig. $2 \mathrm{i}$. Similar thermal stability was observed for AgNWs encapsulated with 4, 10, and $20 \mathrm{~nm}$ of $\mathrm{Al}_{2} \mathrm{O}_{3}$ (Fig. S3). As a result, the conformal $\mathrm{Al}_{2} \mathrm{O}_{3}$ films with the minimized thickness of $2 \mathrm{~nm} \mathrm{Al}_{2} \mathrm{O}_{3}$ highlights the efficiency of this method that prevents effectively the AgNWs from heating failure at a significantly high temperature $\left(250{ }^{\circ} \mathrm{C}\right)$ for a long duration time. Considering the practical application for optoelectronics fabrication processes involving a post-annealing step for considerable long time, it is expected that the $\mathrm{AgNWs} / \mathrm{Al}_{2} \mathrm{O}_{3}$ electrode can be successfully employed in view of its excellent thermal stability.

To quantitatively analyze the efficacy of the encapsulation layer with
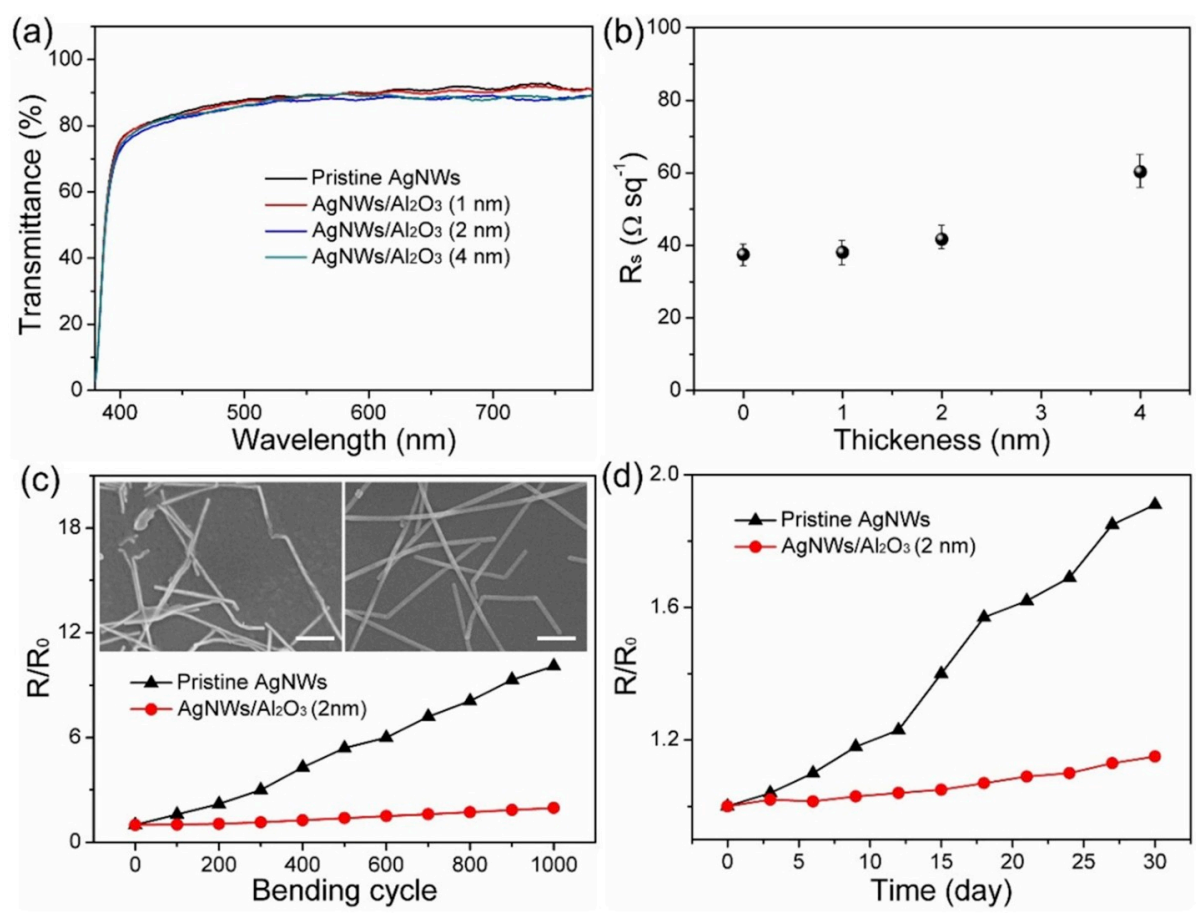

Fig. 3. (a) Transmittance and (b) the corresponding sheet resistance values of $\mathrm{AgNW}$ networks with various thicknesses of $\mathrm{Al}_{2} \mathrm{O}_{3}$ encapsulation layer. All the samples are prepared on PET substrate. (c) Evolution in $R_{s}$ versus the number of cycles during the bending test of $\mathrm{AgNWs}$ and $\mathrm{AgNWs} / \mathrm{Al}_{2} \mathrm{O}_{3}$. Inset: SEM images of pristine AgNWs film (left photo) and AgNWs $/ \mathrm{Al}_{2} \mathrm{O}_{3}$ composite film (right photo) after the bending tests. The scale bar is $400 \mathrm{~nm}$. (d) Evolution in $R_{s}$ of pristine AgNWs and AgNWs $/ \mathrm{Al}_{2} \mathrm{O}_{3}$ composite film at a relative humidity of $35 \%$ and room temperature condition. 
several thicknesses of ALD- $\mathrm{Al}_{2} \mathrm{O}_{3}$ films, the optical and electrical properties of various $\mathrm{AgNWs} / \mathrm{Al}_{2} \mathrm{O}_{3}$ films were then measured. Fig. 3a shows the results of transmittance for the $\mathrm{AgNWs} / \mathrm{Al}_{2} \mathrm{O}_{3}$. The highest average transmittance value of $86.7 \%$ in the visible range was obtained for pristine $\mathrm{AgNWs}$ film. The transmittance of the $\mathrm{AgNWs} / \mathrm{Al}_{2} \mathrm{O}_{3}(1 \mathrm{~nm})$ composite film was $86.1 \%$, quite close to that of the pristine AgNWs. For comparison, the $\mathrm{AgNWs} / \mathrm{Al}_{2} \mathrm{O}_{3}(2$ and $4 \mathrm{~nm})$ showed transmittance of 85.3 and $84.4 \%$, respectively. Fig. $3 \mathrm{~b}$ illustrates the $R_{s}$ of AgNWs electrodes before and after deposition of 1,2 , and $4 \mathrm{~nm} \mathrm{Al}_{2} \mathrm{O}_{3}$. The addition of an insulating $\mathrm{Al}_{2} \mathrm{O}_{3}$ film onto AgNWs could certainly increase the $R_{s}$, it is thus essential to use an ultra-thin $\mathrm{Al}_{2} \mathrm{O}_{3}$ film to minimize this negative effect. In our case, the increase of $R_{S}$ remained small with only $11.3 \%$ after depositing $2 \mathrm{~nm} \mathrm{Al}_{2} \mathrm{O}_{3}$ layer. This indicates that the ultra-thin $\mathrm{Al}_{2} \mathrm{O}_{3}$ coating carried out at the ALD temperature of $110{ }^{\circ} \mathrm{C}$ did not significantly alter the electrical properties of the $\mathrm{Ag}$ nanowire at a certain low thickness. When the thickness of $\mathrm{Al}_{2} \mathrm{O}_{3}$ is up to $4 \mathrm{~nm}$, the $R_{S}$ is dramatically enhanced. As a result, the thickness of $\mathrm{Al}_{2} \mathrm{O}_{3}$ layer should be optimized to the lowest value for which can still show effective thermal protection. It is important to note that the AgNWs networks with a thicknesses of $\mathrm{Al}_{2} \mathrm{O}_{3}$ at $2 \mathrm{~nm}$ remained intact after high temperature annealing, so the following experiments were performed by using AgNWs electrodes coated with $2 \mathrm{~nm}$ of $\mathrm{Al}_{2} \mathrm{O}_{3}$ to ensure optimal performance.

It is known that good air stability and mechanical durability are critical for the flexible organic optoelectronics [32,33]. Here, we investigated the mechanical durability of the pristine AgNWs and optimized AgNWs $/ \mathrm{Al}_{2} \mathrm{O}_{3}\left(2 \mathrm{~nm}\right.$ ) electrode by measuring the $R_{s}$ changes with a bending radius of $5 \mathrm{~mm}$. As shown in Fig. 3c, after 1000 bending cycles, the $R_{s}$ of $\mathrm{AgNWs} / \mathrm{Al}_{2} \mathrm{O}_{3}$ film increased slightly. In contrast, the $R_{S}$ increase of pristine AgNWs films rapidly doubled after only 100 bending cycles and increased about 10 times after 1000 bending cycles. These results confirm the excellent mechanical durability of our $\mathrm{AgNWs} / \mathrm{Al}_{2} \mathrm{O}_{3}$ FTEs. SEM observations were performed on pristine AgNWs and $\mathrm{AgN}$ $\mathrm{W} / \mathrm{Al}_{2} \mathrm{O}_{3}$ samples after the bending test, as shown in the inset of Fig. 3c.
It can be clearly found that part of AgNWs are removed from the substrate after the bending test (see left image), whereas the $\mathrm{AgNWs} / \mathrm{Al}_{2} \mathrm{O}_{3}$ composite film (right) shows a negligible change of morphology and are still well connected (see right image). Such measurements confirm the effect of $\mathrm{Al}_{2} \mathrm{O}_{3}$ on the flexibility of AgNWs electrode.

The long-term storage stability of the pristine AgNWs and AgNWs/ $\mathrm{Al}_{2} \mathrm{O}_{3}$ composite electrode was also demonstrated. Fig. 3d shows the $R_{s}$ variations of the $\mathrm{AgNWs}$ and $\mathrm{AgNWs} / \mathrm{Al}_{2} \mathrm{O}_{3}(2 \mathrm{~nm})$ that were exposed in ambient air and relative humidity of $35 \%$. The $R_{s}$ of the pristine AgNWs network rapidly increased by $23 \%$ in 12 days, while further increase of $91 \%$ in resistance was observed for longer exposure up to 30 days. However, the $R_{s}$ for the AgNWs $/ \mathrm{Al}_{2} \mathrm{O}_{3}(2 \mathrm{~nm})$ composite electrode increased slight $\sim 15 \%$ after exposure under the same experimental condition for 30 days. The possible reason of the significant increase of $R_{s}$ in the case of pristine AgNWs has been reported in the literature, which can be mainly attributed to the corrosions by environmental oxygen and sulfur [34,35]. In the case of $\mathrm{Al}_{2} \mathrm{O}_{3}$, it has been shown to be an excellent barrier material as metal oxide [36]. The good intrinsic corrosion resistance of $\mathrm{Al}_{2} \mathrm{O}_{3}$ coated around the AgNWs can impede the oxidation of the AgNWs and their junctions, consequently increasing the stability for the $\mathrm{AgNWs} / \mathrm{Al}_{2} \mathrm{O}_{3}$ electrodes.

To evaluate the interface between AgNWs and the ultra-thin $\mathrm{Al}_{2} \mathrm{O}_{3}$ layer, high-resolution TEM observations were performed on the crosssection of $\mathrm{AgNWs} / \mathrm{Al}_{2} \mathrm{O}_{3}$ composite film. Fig. 4 is a set of TEM images (a) and (b) for the two samples encapsulated by $\mathrm{Al}_{2} \mathrm{O}_{3}$ layer with thicknesses of 2 and $4 \mathrm{~nm}$. Both images show the cross-section of an AgNW with the electron beam parallel to the revolution axis of the wires. This direction corresponds to the [110] crystallographic direction (according to Miller index) of AgNW. It is interesting to note that the NWs are both divided into several domains with triangular shapes, separated by twin boundaries and a cross point of these boundaries at the middle of the NW. The presence of a $2 \mathrm{~nm}$ layer in Fig. 4a with a different grey contrast on the top of the wire suggests that the $\mathrm{Al}_{2} \mathrm{O}_{3}$ layer covers smoothly the nanowire, giving evidence of the high uniformity and

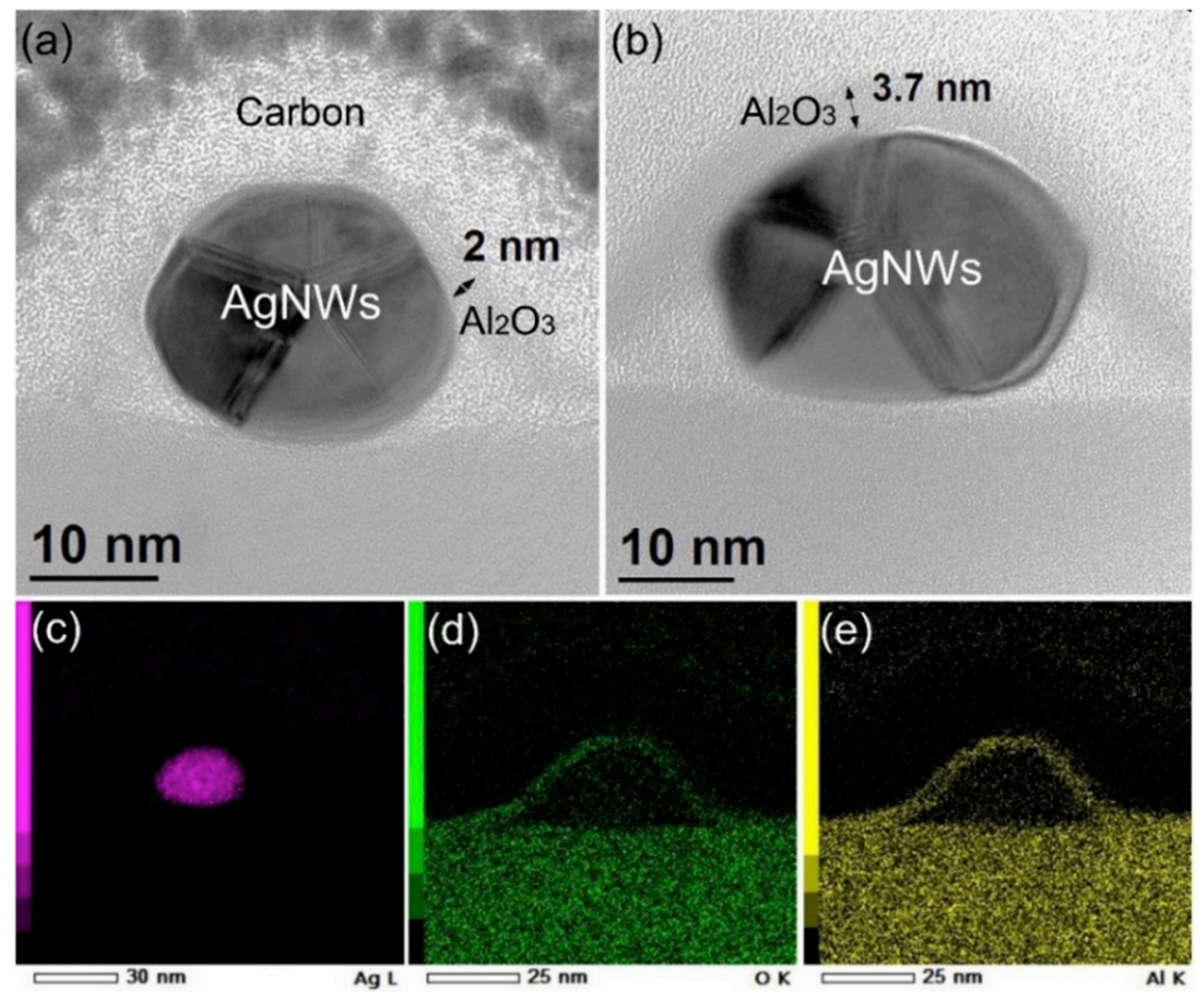

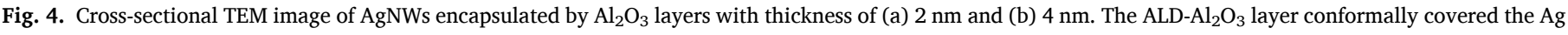
nanowires. (c-e) Energy-dispersive X-ray spectroscopy (EDS) mapping images of the $\mathrm{AgNWs} / \mathrm{Al}_{2} \mathrm{O}_{3}$ composite film. 
excellent quality of the ALD deposition. Similar $\mathrm{Al}_{2} \mathrm{O}_{3}$ layer with a thickness of $\sim 4 \mathrm{~nm}$ can be observed in Fig. $4 \mathrm{~b}$, indicating the precise control over the thickness at the nanoscale of ALD. Furthermore, chemical analyses were performed to confirm the above statements. Fig. 4c, d and e illustrate STEM EDX mappings for $\mathrm{Ag}, \mathrm{O}$ and $\mathrm{Al}$, respectively, in the $\mathrm{AgNWs} / \mathrm{Al}_{2} \mathrm{O}_{3}$ composite film. The former one shows undoubtedly the AgNWs and the two latter ones reveal the alumina layer covering the AgNWs, providing a direct evidence of the successful deposition. The EDS analysis confirms that the polymeric residues from the AgNWs ink remained beneath the AgNWs after the coating of the $\mathrm{Al}_{2} \mathrm{O}_{3}$ layer.

To further demonstrate the viability of the $\mathrm{AgNWs} / \mathrm{Al}_{2} \mathrm{O}_{3}$ composite film as a FTE, nonfullerene OSCs using $\mathrm{AgNWs} / \mathrm{Al}_{2} \mathrm{O}_{3}$ FTE were fabricated with a typical structure, as shown in Fig. 5a. The bulk heterojunction materials consisting of PBDB-T:ITIC blends were employed as the donor and acceptor material to ensure high efficiency of flexible OSCs. Fig. $5 \mathrm{~b}$ shows the $J-V$ characteristics of the resulting OSC devices using AgNWs-based FTEs with or without the optimized (2 nm) $\mathrm{Al}_{2} \mathrm{O}_{3}$ encapsulation layer. The optimal $\mathrm{AgNWs} / \mathrm{Al}_{2} \mathrm{O}_{3}$-based nonfullerene OSC measured under AM $1.5 \mathrm{G}\left(100 \mathrm{~mW} \mathrm{~cm}^{-2}\right)$, shows a short-circuit current density $\left(J_{S C}\right)$ of $12.35 \mathrm{~mA} \mathrm{~cm}{ }^{-2}$ with an open-circuit voltage $\left(V_{O C}\right)$ of $0.89 \mathrm{~V}$ and a fill factor (FF) of $63.90 \%$, giving a PCE of $7.03 \%$. The PCE value is lower than the pristine AgNWs based reference sample $(7.29 \%$, with $J_{S C}=12.66 \mathrm{~mA} \mathrm{~cm}^{-2}, V_{O C}=0.89 \mathrm{~V}$, and $\mathrm{FF}=64.84 \%$ ). The slightly inferior PCE of flexible cells using $\mathrm{AgNWs} / \mathrm{Al}_{2} \mathrm{O}_{3}$ anodes is mainly attributed to their lower $J_{S C}$ than that of pristine AgNWs based devices, which is related to the increased sheet resistance induced by the coating of $\mathrm{Al}_{2} \mathrm{O}_{3}$. The detailed parameters of the devices were summarized in
Table 1. The EQE spectra of two different devices are shown in Fig. 5c, the $\mathrm{AgNWs} / \mathrm{Al}_{2} \mathrm{O}_{3}$-based device had a close quantum efficiency comparing with that of the pristine AgNWs-based device in visible light wavelength range. Moreover, it should be mentioned that significantly improved mechanical/thermal/storage stabilities can be further obtained with such novel FTEs, which are essential for the emerging flexible optoelectronics requiring high temperature fabrication processing [37].

To investigate the device mechanical stability, the flexible OSCs are measured for the bending test with different bending times, as shown in Fig. 5d. After finishing 1000 consecutive bending tests with the bending radius of $5 \mathrm{~mm}$, a significant decrease of the device efficiency using pristine AgNWs electrode was observed due to the relatively low mechanical stability of AgNWs. Meanwhile, the flexible OSCs employing $\mathrm{AgNWs} / \mathrm{Al}_{2} \mathrm{O}_{3}$ electrode show considerable good mechanical endurance and can maintain over $90.1 \%$ of the original PCE under the same bending test. As a result, the AgNWs $/ \mathrm{Al}_{2} \mathrm{O}_{3}$ based flexible OSCs shows desirable mechanical stability compared to pristine AgNWs based devices.

The thermal stability measurement were also carried out at the

Table 1

Summary of flexible nonfullerene OSC characteristics, averaged from $>10$ cells.

\begin{tabular}{lllll}
\hline & $\mathrm{V}_{\mathrm{oc}}[\mathrm{V}]$ & $\mathrm{J}_{\mathrm{sc}}\left[\mathrm{mA} \mathrm{cm}^{-2}\right]$ & $\mathrm{FF}[\%]$ & PCE [\%] \\
\hline $\mathrm{AgNWs}$ & $0.89 \pm 0.01$ & $12.66 \pm 0.2$ & $64.84 \pm 0.3$ & $7.29 \pm 0.2$ \\
$\begin{array}{c}\mathrm{AgNWs} / \mathrm{Al}_{2} \mathrm{O}_{3}(2 \\
\mathrm{nm})\end{array}$ & $0.89 \pm 0.01$ & $12.35 \pm 0.4$ & $63.90 \pm 0.4$ & $7.03 \pm 0.2$ \\
& & & & \\
\hline
\end{tabular}
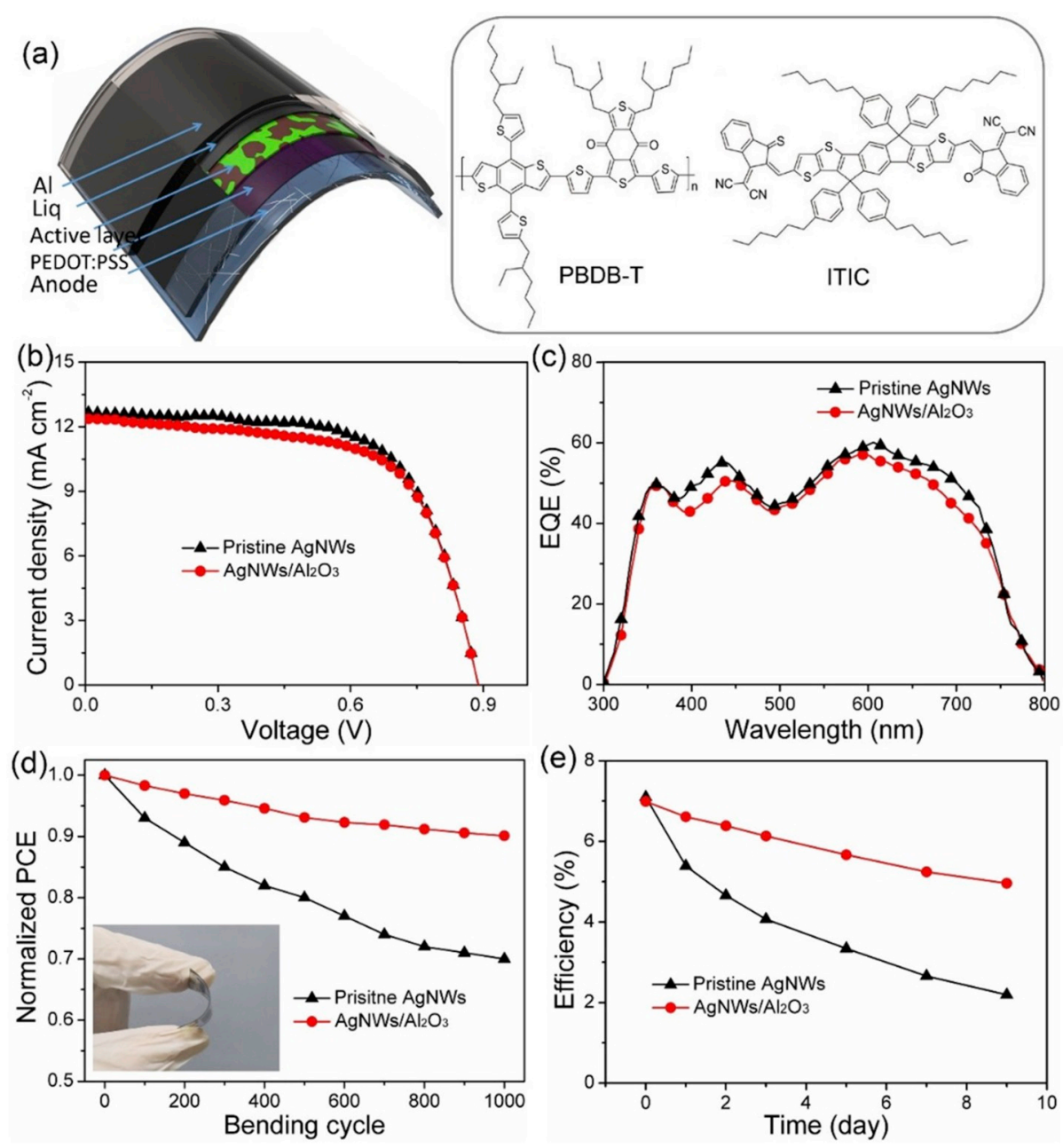

Fig. 5. (a) Device architecture of the nonfullerene OSCs on flexible AgNWs-based PET substrate and chemical structures of the donor and the acceptor used in this study. (b) $J-V$ characteristics and (c) the corresponding EQE spectra of the flexible nonfullerene device based on the AgNWs $/ \mathrm{Al}_{2} \mathrm{O}_{3}$ composite electrode as well as the reference cell based on the pristine AgNWs. (d) Normalized PCE of the flexible nonfullerene OSCs after different bending cycles. The inset shows the corresponding device photographs. (e) PCE decays of the resulting flexible encapsulated nonfullerene OSCs as a function of the storage time with various AgNWs based electrodes under ambient conditions. 
temperature of $60{ }^{\circ} \mathrm{C}$ which is defined as a reference temperature for organic photovoltaic cell in a nitrogen atmosphere in every $10 \mathrm{~min}$ [38]. The results are shown in Fig. S4. After the thermal stability test, the efficiency of the devices based on pristine AgNWs decreased from 7.25\% to $2.77 \%$, which retained only $38 \%$ of its original values. On the contrary, the devices using $\mathrm{AgNWs} / \mathrm{Al}_{2} \mathrm{O}_{3}$ composite electrode demonstrated relatively better thermal stability. The average efficiency of the AgNWs $/ \mathrm{Al}_{2} \mathrm{O}_{3}$ based devices decayed from $7.02 \%$ to $3.83 \%$, maintaining $55 \%$ of its original value under the same thermal stability test. Since the thermal stability of nonfullerene OSC devices could be very sensitive to active layer morphology factors, the improved thermal stability is likely attributed the composite electrode architecture, which functioned as a heat-insulating scaffold to restrain the reorganization of the active materials when heated [39].

Long-time air stability is also investigated and the result is shown in Fig. 5e, the encapsulated devices based on pristine AgNWs electrode are completely degraded after 9 days, retaining only $30 \%$ of the original efficiency, which is mainly caused by the corrosion of AgNWs from the acidic PEDOT:PSS which is employed as HIL. On the contrary, the flexible OSC device using $\mathrm{AgNWs} / \mathrm{Al}_{2} \mathrm{O}_{3}$ composite anode show enhanced environmental stability, resulting in over $71 \%$ of the pristine PCE after 9 days. It is worth noting that the moisture can easily access the active layer through the PEDOT:PSS due to its hygroscopicity property $[40,41]$. However, the $\mathrm{Al}_{2} \mathrm{O}_{3}$ coating can effectively prevent water eroding the nonfullerene active layer. As a result, the excellent mechanical, thermal and long-term air stabilities of flexible OSCs with a $\mathrm{PCE}>7 \%$ are clearly demonstrated.

Finally, to demonstrate the compatibility of the $\mathrm{AgNWs} / \mathrm{Al}_{2} \mathrm{O}_{3}$ composite electrode in light-emitting devices, we fabricated a flexible PLED using an as-produced AgNWs $/ \mathrm{Al}_{2} \mathrm{O}_{3}$ as anodes onto a PET substrate. The molecular structure of SY-PPV is illustrated in Fig. S5. The device architecture is illustrated in Fig. 6a. Fig. 6b and c shows the corresponding characteristics of resulting PLED devices. Both devices with pristine $\mathrm{AgNWs}$ and $\mathrm{AgNWs} / \mathrm{Al}_{2} \mathrm{O}_{3}$ composite anodes showed low leakage currents with a turn on voltage of 3.2 and $3.4 \mathrm{~V}$ due to the high conductivity of AgNWs. The measured maximum luminance were 14500.0 and $13576.4 \mathrm{~cd} \mathrm{~m}^{-2}$ for the two flexible PLEDs, while the maximum $\mathrm{CE}$ values of 8.47 and $7.26 \mathrm{~cd} \mathrm{~A}^{-1}$ were achieved (see Table 2). The corresponding Commission Internationale de L'Eclairage (CIE) coordinates was located at $(0.41,0.56)$ (Fig. S6). More importantly, the device employing $\mathrm{AgNWs} / \mathrm{Al}_{2} \mathrm{O}_{3}$ as composite electrode exhibited good mechanical stability, remaining $79 \%$ of the initial brightness of $2000 \mathrm{~cd} \mathrm{~m}^{-2}$ after 1000 bending cycles with the same bending radius $(5 \mathrm{~mm})$. On the contrary, the pristine AgNWs network maintained merely $58 \%$ under the same bending condition. The superior mechanical stability can be explained by the mechanical flexibility of $\mathrm{AgNWs} / \mathrm{Al}_{2} \mathrm{O}_{3}$ composite electrode, as measured previously. Another possible reason for the decrease in brightness can be attributed to the degradation of the functional layers in the devices, such as the evaporated interficial layer or metal electrode, which can be affected by the mechanical deformation [42].

\section{Conclusion}

In conclusion, we have demonstrated that the $\mathrm{AgNWs} / \mathrm{Al}_{2} \mathrm{O}_{3}$ composite electrodes provide an effective means to improve the stability of both flexible nonfullerene OSCs and PLEDs devices requiring high processing temperatures. The synergy of solution-processed AgNWs and atomic layer deposited $\mathrm{Al}_{2} \mathrm{O}_{3}$ led to a transparent conductor with excellent optical and electrical properties, superb thermal, mechanical and environmental features, which simultaneously overcomes the shortcomings of AgNWs-based FTEs. Remarkably, high PCEs up to $7.03 \%$ in flexible OSCs as well as outstanding EL efficiencies of up to

Table 2

Summary of flexible PLED characteristics.

\begin{tabular}{lllll}
\hline & $\mathrm{V}_{\text {on }}[\mathrm{V}]$ & $\mathrm{L}_{\max }\left[\mathrm{cd} \mathrm{m}^{-2}\right]$ & $\mathrm{CF}\left[\mathrm{cd} \mathrm{A}^{-1}\right]$ & $\mathrm{EL}[\mathrm{nm}]$ \\
\hline AgNWs & 3.2 & 14500 & 8.47 & 540 \\
AgNWs $/ \mathrm{Al}_{2} \mathrm{O}_{3}$ & 3.4 & 13567 & 7.26 & 540 \\
\hline
\end{tabular}
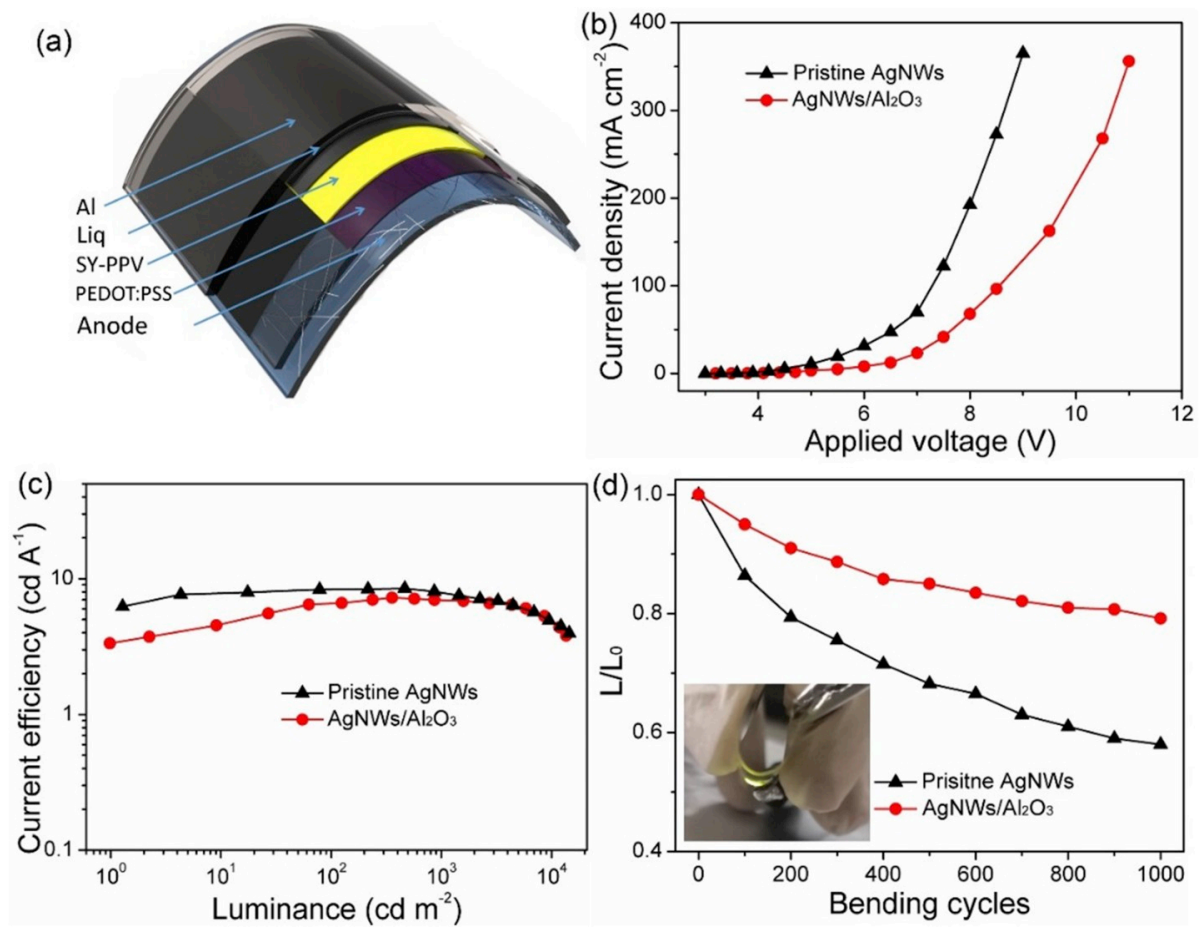

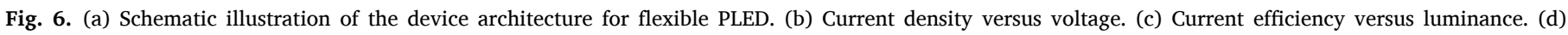

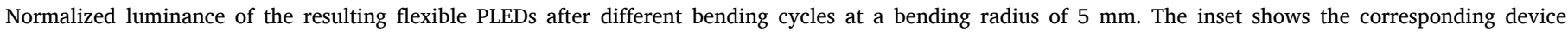
photographs. 
$7.26 \mathrm{~cd} \mathrm{~A} \mathrm{~A}^{-1}$ in super yellow based PLEDs built on the AgNWs $/ \mathrm{Al}_{2} \mathrm{O}_{3}$ electrodes were achieved. Finally, the flexible devices demonstrated excellent mechanical and storage stability. We thus believe that this work demonstrates a multifunctional platform, which could provide great potential in a wide variety of optoelectronic applications.

\section{Author contributions}

T.X. conceived the idea. S.L.W. and S.W.W. designed the experiments, performed the device fabrication and corresponding data analysis. Z.L., H.C. and H.L assisted with the device characterization and data analysis. X.P., and F.G. conducted AFM and TEM measurements. S. L.W., and T.X. wrote the manuscript. F.Z., and M.T. provided helpful discussions during the project. B.W. and T.X. supervised the project. All authors contributed to the data analysis, discussed the results, and commented on the manuscript.

\section{Declaration of competing interest}

The authors declare that they have no known competing financial interests or personal relationships that could have appeared to influence the work reported in this paper.

\section{Acknowledgements}

This work was supported by Natural Scientific Foundation of Shanghai (19ZR1419500), Science and Technology Commission of Shanghai Municipality Program (19DZ2281000) and the National Natural Science Foundation of China $(61775130,11974236)$. X. Portier is grateful to the "Agence Nationale de la Recherche" (ANR) for the EQUIPEX "GENESIS" grant "ANR-11-EQPX-0020" in the frame of the "Investissements d'avenir". He also wants to thank the "Fond Europeen de Développement Régional" (FEDER) and the Normandie Region. S.L. Wang thanks the China Scholarship Council (CSC) for financial support.

\section{References}

[1] Y. Woo, W. Hong, S.Y. Yang, H.J. Kim, J.H. Cha, J.E. Lee, S.Y. Choi, Adv. Electron. Mater. 4 (2018) 1800251.

[2] Y. Miao, K. Wang, B. Zhao, L. Gao, P. Tao, X. Liu, F. Zhu, Nanophotonics 7 (2018) 295-304.

[3] S. Wang, M. Qiao, Z. Ye, D. Dou, M. Chen, Y. Peng, C. Li, iScience 9 (2018) $532-541$.

[4] H.W. Bae, S.K. Kim, S. Lee, M.G. Song, R. Lampande, J.H. Kwon, Adv. Electron. Mater. (2019) 1900620.

[5] L. Tang, S. Cheng, L. Zhang, H. Mi, L. Mou, S. Yang, X. Jiang, iScience 4 (2018) 302-311.

[6] S. Jiang, P.X. Hou, M.L. Chen, B.W. Wang, D.M. Sun, D.M. Tang, K.P. Tai, Sci. Adv. 4 (2018) 9264.
[7] S.R. Shin, H.B. Lee, W.Y. Jin, K.J. Ko, S. Park, S. Yoo, J.W. Kang, J. Mater. Chem. C. 6 (2018) 5444-5452.

[8] S. Choi, S.J. Kim, C. Fuentes-Hernandez, B. Kippelen, Opt. Express 19 (2011) 793-803.

[9] T.H. Han, Y. Lee, M.R. Choi, S.H. Woo, S.H. Bae, B.H. Hong, T.W. Lee, Nat. Photonics 6 (2012) 105

[10] D. Zhang, K. Ryu, X. Liu, E. Polikarpov, J. Ly, M.E. Tompson, C. Zhou, Nano Lett. 6 (2006) 1880-1886.

[11] M.S. White, M. Kaltenbrunner, E.D. Głowacki, K. Gutnichenko, G. Kettlgruber, I. Graz, Z. Major, Nat. Photonics 7 (2013) 811.

[12] G. Jeong, S. Jung, Y. Choi, J. Lee, J. Seo, D.S. Kim, H. Park, J. Mater. Chem. 6 (2018) 24805-24813.

[13] J.H. Kim, J.W. Park, ACS Appl. Mater. Interfaces 10 (2018) 9704-9717.

[14] W. Gaynor, S. Hofmann, M.G. Christoforo, C. Sachse, S. Mehra, A. Salleo, P. Peumans, Adv. Mater. 25 (2013) 4006-4013.

[15] J. Liang, L. Li, K. Tong, Z. Ren, W. Hu, X. Niu, Q. Pei, ACS Nano 8 (2014) 1590-1600.

[16] S. HwanáKo, Nanoscale 9 (2017) 1978-1985.

[17] S. Wang, Y. Zhao, H. Lian, C. Peng, X. Yang, Y. Gao, T. Xu, Nanophotonics 8 (2019) 297-306.

[18] C. Yang, H. Gu, W. Lin, M.M. Yuen, C.P. Wong, M. Xiong, B. Gao, Adv. Mater. 23 (2011) 3052-3056.

[19] T.B. Song, Y. Chen, C.H. Chung, Y. Yang, B. Bob, H.S. Duan, Y. Yang, ACS Nano 8 (2014) 2804-2811.

[20] Y.S. Kim, E.J. Lee, J.T. Lee, D.K. Hwang, W.K. Choi, J.Y. Kim, RSC Adv. 6 (2016) 64428-64433.

[21] S. Chen, L. Song, Z. Tao, X. Shao, Y. Huang, Q. Cui, X. Guo, Org. Electron. 15 (2014) 3654-3659.

[22] A. Kim, Y. Won, K. Woo, C.H. Kim, J. Moon, ACS Nano 7 (2013) 1081-1091.

[23] P. Poodt, R. Knaapen, A. Illiberi, F. Roozeboom, A. van Asten, J. Vac. Sci. Technol. A: Vac., Surf., Film. 30 (2012) 142.

[24] O. Ibrahim Elmi, O. Cristini-Robbe, M.Y. Chen, B. Wei, R. Bernard, D. Yarekha, E. Okada, S. Ouendi, X. Portier, F. Gourbilleau, T. Xu, D. Stiévenard, Nanotechnology 29 (2018) 285403.

[25] W.C. Wang, M.C. Tsai, J. Yang, C. Hsu, M.J. Chen, ACS Appl. Mater. Interfaces 7 (2015) 10228-10237.

[26] B. Wei, Z.Y. Tang, S.L. Wang, C.P. Qin, C.Y. Li, X.W. Ding, Y. Gao, X. Portier, F. Gourbilleau, D. Stiévenard, T. Xu, Nanotechnology 29 (2018) 395204.

[27] B. Hwang, Y. An, H. Lee, E. Lee, S. Becker, Y.H. Kim, H. Kim, Sci. Rep. 7 (2017) 41336 .

[28] D. Chen, J. Liang, C. Liu, G. Saldanha, F. Zhao, K. Tong, Q. Pei, Adv. Funct. Mater. 25 (48) (2015) 7512-7520.

[29] H.G. Im, J. Jin, J.H. Ko, J. Lee, J.Y. Lee, B.S. Bae, Nanoscale 6 (2) (2014) 711-715.

[30] G. Guisbiers, S. Pereira, Nanotechnology 18 (43) (2007) 435710.

[31] S.D. Standridge, G.C. Schat, J.T. Hupp, Langmuir 25 (5) (2009) 2596-2600.

[32] X.Y. Zeng, Q.K. Zhang, R.M. Yu, C.Z. Lu, Adv. Mater. 22 (40) (2010) 4484-4488.

[33] B. Hwang, H.A.S. Shin, T. Kim, Y.C. Joo, S.M. Han, Small 10 (16) (2014) 3397-3404.

[34] E. Langereis, M. Creatore, S.B.S. Heil, Van De, M.C.M. Sanden, W.M.M. Kessels, Appl. Phys. Lett. 89 (8) (2006), 081915.

[35] Y. Ahn, Y. Jeong, Y. Lee, ACS Appl. Mater. Interfaces 4 (12) (2012) 6410-6414.

[36] U.S. Lee, J.S. Choi, B.S. Yang, S. Oh, Y.J. Kim, M.S. Oh, H.J. Kim, ECS. Solid. State. Lett. 2 (6) (2013) R13-R15.

[37] L. Li, J. Liang, S.Y. Chou, X. Zhu, X. Niu, Q. Pei, Sci. Rep-UK. 4 (2014) 4307.

[38] L. Derue, O. Dautel, A. Tournebize, M. Drees, H. Pan, S. Berthumeyrie, A. Rivaton, Adv. Mater. 26 (2014) 5831-5838.

[39] R. Wang, S.Y. Chang, L. Meng, W. Huang, J.W. Lee, H.W. Cheng, C. Zhu, Matter 1 (2) (2019) 402-411.

[40] S. Shao, J. Liu, J. Bergqvist, S. Shi, C. Veit, U. Wuerfel, F. Zhang, Adv. Energy Mater. 3 (3) (2013) 349-355.

[41] H. Zhou, Y. Wang, J. Zhang, Z. Yu, Y. Li, L. Tan, Y. Chen, J. Mater. Chem. C. 6 (2) (2018) 312-319.

[42] S. Wang, J. Yang, T. Xu, D. Dou, Z. Tang, Z. Gao, R. Bachelot, Org. Electron. 64 (2019) 146-153. 